\title{
"A Flexible Infrastructure for Dynamic Power Control of Electric Vehicle Battery Chargers"
}

IEEE Transactions on Vehicular Technology, vol.65, no.6, pp.4535-4547, June 2016.

http://ieeexplore.ieee.org/xpl/articleDetails.jsp?tp=\&arnumber=7258394

ISSN: 0018-9545

DOI 10.1109/TVT.2015.2478151

This material is posted here with permission of the IEEE. Such permission of the IEEE does not in any way imply IEEE endorsement of any of Group of Energy and Power Electronics, University of Minho, products or services. Internal or personal use of this material is permitted. However, permission to reprint/republish this material for advertising or promotional purposes or for creating new collective works for resale or redistribution must be obtained from the IEEE by writing to pubs-permissions@ieee.org. By choosing to view this document, you agree to all provisions of the copyright laws protecting it.

(C) 2014 IEEE 


\title{
A Flexible Infrastructure for Dynamic Power Control of Electric Vehicle Battery Chargers
}

\author{
Vítor Monteiro, Student Member, IEEE, João Paulo Carmo, \\ J. G. Pinto, Student Member, IEEE, and João L. Afonso, Member, IEEE
}

\begin{abstract}
This paper proposes a Flexible Infrastructure for Dynamic Power Control (FIDPC) of Electric Vehicle (EV) Battery Chargers. This infrastructure dynamically adjusts the EV battery charger current, according to the power demand of the home wherein the vehicle is plugged. An infrastructure was implemented to validate this proposal. Such infrastructure is composed by an EV battery charger and a communication system based on a Radio Frequency interface. The battery charger has nominal power of $3.6 \mathrm{kVA}$ and operates with sinusoidal current and unitary total power factor, while the RF interface provides continuous data flow to the battery charger with information about the home total current consumption (rms value). Experimental tests were performed under realistic conditions to validate the concept behind the proposed FIDPC. These tests served to assess the behavior of the EV battery charger with dynamic power control on a single-phase, $230 \mathrm{~V}$, $16 \mathrm{~A}, 50 \mathrm{~Hz}$ residential electrical installation. The experimental results confirm the quick time response of the FIDPC even when working under heavy home load variations.
\end{abstract}

Index Terms-Electric Vehicles, Home-to-Vehicle (H2V), RF Communication, Power Quality, Smart Grids, Vehicle-to-Grid (V2G).

\section{INTRODUCTION}

$\mathrm{T}$ HE electric mobility represents a new paradigm for the transporting sector [1][2]. This includes the use of Hybrid Electric Vehicles (HEVs) and Electric Vehicles (EVs), which can be combined with renewable energy [3][4] and simultaneously integrated into the future smart grids [5]. Nevertheless, the integration of EVs into smart grids will be strongly dependent of major technological issues. Few of these issues include the innovation in energy storage systems [6], battery charging strategies [7] and communications field [8]. However, the deregulated proliferation of EVs can cause power quality problems in the power grid [9]. On the other

"Copyright (c) 2015 IEEE. Personal use of this material is permitted. However, permission to use this material for any other purposes must be obtained from the IEEE by sending a request to pubs-permissions@iee.org. "

This work has been supported by FCT - Fundação para a Ciência e Tecnologia in the scope of the project: PEst-UID/CEC/00319/2013. Mr. Vítor Monteiro was supported by the doctoral scholarship SFRH/BD/80155/2011 granted by the FCT agency.

Vítor Monteiro, J. G. Pinto, and João L. Afonso are with Centro Algoritmi, University of Minho, Dept. Industrial Electronics, 4800-058 Guimarães, Portugal; emails: vmonteiro@dei.uminho.pt, gpinto@dei.uminho.pt and jla@dei.uminho.pt.

João Paulo Carmo is with University of São Paulo (USP), Dept. of Electrical Engineering (SEL), Av. Trabalhador São-Carlense, CEP 13566590, São Carlos - SP, BRAZIL; email: jcarmo@sc.usp.br hand, the regulated proliferation can result on benefits to the EV driver and to the power grid management [10][11]. An example of such benefits can be observed in [12], where is proposed a control strategy for charging the batteries of the EVs considering the charging schedule uncertainty and the energy price variation. These benefits are mainly related with the bidirectional power flow and exchanged data between the power grid and the EV battery charger [13]. It must be noted that, if the EV battery charger is bidirectional, it can consume or supply energy from or to the power grid, respectively. Thereby, besides the battery charging process (i.e., G2V - Grid-to-Vehicle mode), part of the energy previously stored in the batteries can be delivered back towards the power grid (i.e., V2G - Vehicle-to-Grid mode) [14]. The V2G operation mode must take into account the power grid requirements and the benefits to the EV driver. This operation considers few critical issues, e.g., the price of energy to sell or to buy, and the battery State-of-Charge (SoC). The main advantages behind the $\mathrm{V} 2 \mathrm{G}$ operation mode are related with load-shedding, ancillary services and electric utility [15][16][17]. Additionally, the interactivity of EVs with smart grids will demand efforts related to the development of smart homes [18]. Thus, it is expected an increase in the research and development of Home-to-Vehicle (H2V) technologies for application in smart homes to allow the implementation of energy management and efficiency solutions [19][20]. In this context, the smart homes are facing decision making problems, requiring the best possible decision towards the integration of smart devices in a hierarchical architecture in smart grids context without neglecting the power grid stability and the quality-of-service [21][22]. The development of these kind of technologies for EVs is more pertinent for researching after knowing that private vehicles are parked in average $95 \%$ of the time [23], and at the same time, a significant majority of them are parked at home between $8 \mathrm{PM}$ and $7 \mathrm{AM}$ [24]. In most of the cases, the battery charging process is performed during this period of the day, in which the EV represents an extra residential load during this period. For example, it is during this period that a significant number of domestic apparatus (TVs, lights, washing machines, and so on) are turned on and off according to the user preferences. The monitoring of the EV battery charging process is not the only advantage brought by the smart home concept. In fact, there are other advantages, where the most important is the one associated with the possibility of the EVs interact with the 
home. Therefore, the main contribution of this paper is a flexible infrastructure for a dynamic control of the EV battery charging process, according to the current required by the home loads. Nevertheless, other important contribution is the controlled operation as V2G in a smart home context, which contributes to avoid trips in the main circuit breaker when the home current exceeds the maximum allowed value. The context of these contributions is illustrated by the system architecture presented in Fig. 1, where $i_{G}$ represents the grid current, $i_{L D}$ the home loads current, and $i_{E V}$ the EV battery charger current. As it can be seen from the system architecture, the EV battery charger current is dynamically adjusted according with the changes in the totality of the home loads current. This dynamic adjustment is a key-contribution to maintain the grid current with a constant rms value. Moreover, the EV battery charger current can be adjusted in both $\mathrm{H} 2 \mathrm{~V}$ and $\mathrm{V} 2 \mathrm{G}$ operation modes without neglecting the power quality.

A data communication solution for sending the rms value of the current measured in the home towards the EV battery charger is a key point to achieve the aforementioned goal. For such purpose, there are available few options of communication systems for providing reliable data between the electrical switchboard inside the home and the EV battery charger, such as Radio-Frequency (RF), Power Line Communication (PLC) and Wi-Fi. The RF-based solution was selected due to its intrinsic simplicity of implementation, adaptation to different scenarios, independence of internet communication, low-prototyping time, but most important, low-cost of implementation [25]. In this context, this paper presents a Flexible Infrastructure for Dynamic Power Control (FIDPC) supported on RF communication for achieving a controllable EV battery charging process. As illustrated in Fig. 1, the RF transmitter is installed in the home electrical switchboard, while the RF receiver is installed in the EV battery charger. This FIDPC was experimentally validated with the help of a prototype especially developed for such purpose. Despite the proposed FIDPC having been idealized and experimentally validated in a home scenario, it is important to note that it can also be integrated in the future smart grids in order to allow adjusting the EV battery charging process.

The remainder of this paper is organized as follows. The $\mathrm{H} 2 \mathrm{~V}$ and $\mathrm{V} 2 \mathrm{G}$ operation modes are presented in section II, while section III presents a case study and a simulation analysis. Section IV presents the system implementation, describes the control algorithms, and details the proposed EV battery charger hardware and the communication system. The experimental results in steady state and in transient response are presented and discussed in section V. Finally, the conclusions are presented in section VI.

\section{System ARCHITECTURE}

Fig. 1 illustrates the system architecture of the proposed FIDPC, which is composed by the home electrical switchboard including the supporting RF module (transmitter) and the EV battery charger (where is installed the RF

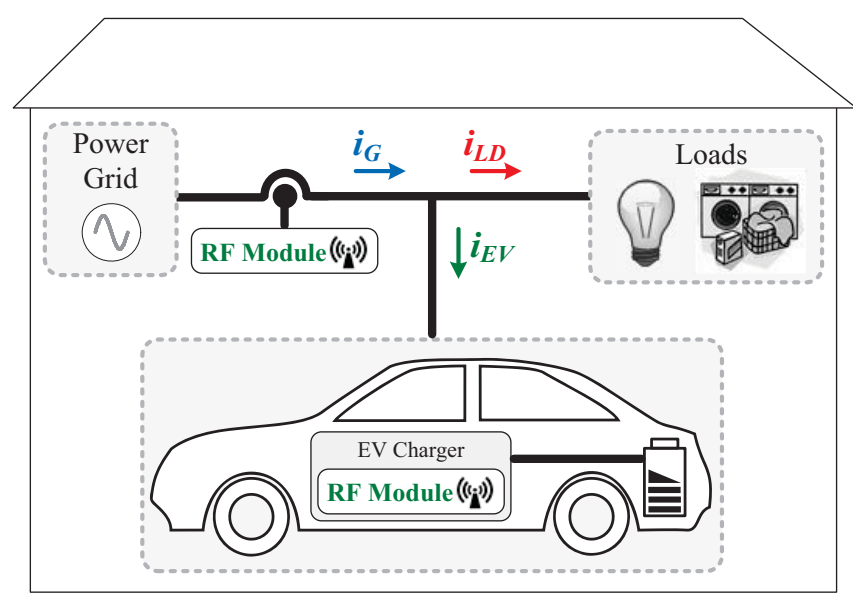

Fig. 1. System architecture of the proposed Flexible Infrastructure for Dynamic Power Control (FIDPC) of Electric Vehicles Battery Chargers.

receiver). This infrastructure is designed to operate in accordance with $\mathrm{H} 2 \mathrm{~V}$ and $\mathrm{V} 2 \mathrm{G}$ technologies. The EV battery charger can recharge the EV battery when the $\mathrm{H} 2 \mathrm{~V}$ mode is selected. Alternatively, the energy can flow in the reverse direction when the $\mathrm{V} 2 \mathrm{G}$ mode is selected, i.e., the energy stored in the batteries can be delivered to the power grid. The EV battery charger operates with sinusoidal current waveform in the ac side for both $\mathrm{H} 2 \mathrm{~V}$ and $\mathrm{V} 2 \mathrm{G}$ operation modes, contributing to the power quality in electrical power grids. The architecture of the FIDPC proposed in this paper intends to adjust the EV battery charger current $\left(i_{E V}\right)$ as function of the current required by the other electrical loads inside the home $\left(i_{L D}\right)$. So, the control of the EV battery charger current $\left(i_{E V}\right)$ is performed in its digital control system according to the home current $\left(i_{G}\right)$ provided by the RF module installed in the electrical switchboard. This contribution is important when looking that nowadays, the common situation is to have the energy flowing from the power grid towards the loads of the home without any control, and simply limited by the contracted power for the home. The implementation of this control strategy by the FIPDC avoids the electrical switchboard overload.

\section{A. Home-to-Vehicle (H2V) Operation Mode}

In the $\mathrm{H} 2 \mathrm{~V}$ operation mode the power flows from the power grid to the EV battery charger. The charging power of the EV battery charger is function of the power demand profile inside the home, and is established that the maximum consumed power in the EV battery charger corresponds to the power contracted with the electricity service provider. Usually, the electricity service provider installs a circuit breaker rated to the nominal current in order to guarantee that the contracted power is never exceeded. Therefore, the circuit breaker trips every time that the home current exceeds the limit during a short period of time. This is the reason why the current is the variable to be measured and tracked. This is done by measuring the rms value of the home current, followed by its transmission to the EV battery charger. A current sensor, a microcontroller and an RF communication module are used in the execution of these procedures (i.e., the current measuring 


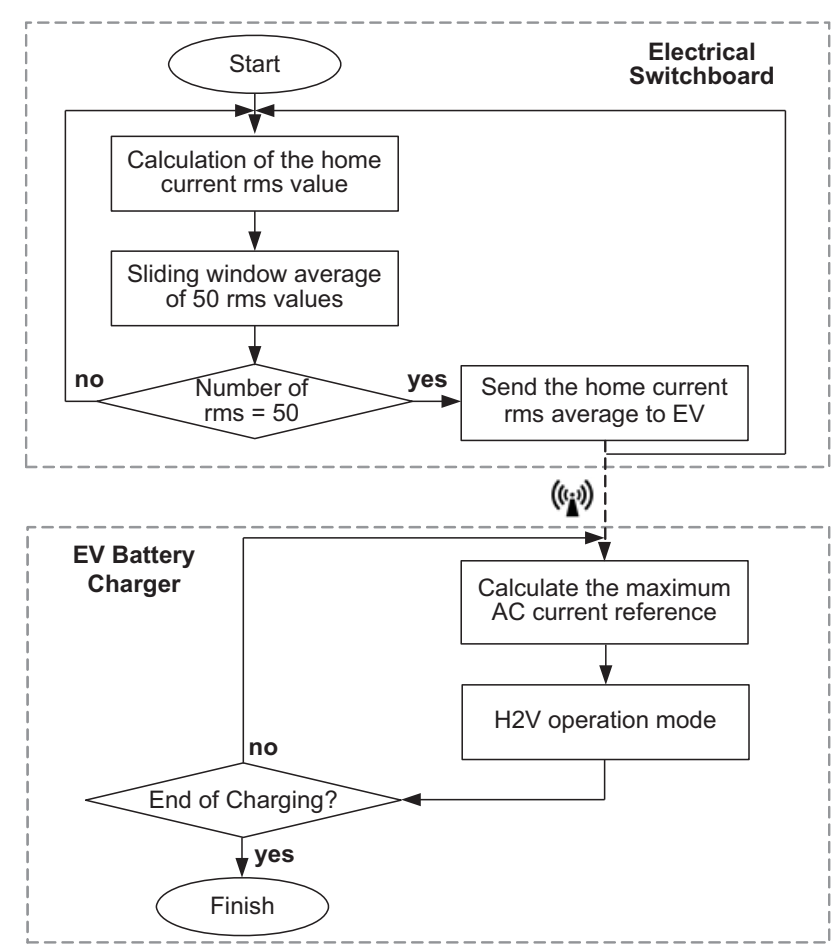

Fig. 2. Control algorithm of the proposed FIDPC architecture during the $\mathrm{H} 2 \mathrm{~V}$ operation mode.

and data transmission). The flowchart in Fig. 2 illustrates the control algorithm during the $\mathrm{H} 2 \mathrm{~V}$ operation mode. In this mode, the current is measured through a current sensor installed inside the home electrical switchboard. The current signal is sampled at the frequency $f_{s}=1.6 \mathrm{kHz}$, in order to acquire 32 samples of the instantaneous current per $50 \mathrm{~Hz}$ cycle. This minimum number of samples is intended to reduce the effect of time discretization and, thus, to obtain a reliable measure of the rms value. This minimum number of samples is in accordance with the International Standard IEC 62053-21. It must be noted that the rms value of the current is calculated for each $50 \mathrm{~Hz}$ cycle.

\section{B. Vehicle-to-Grid (V2G) Operation Mode}

During the V2G operation mode the energy flows from the EV battery charger towards the power grid. The V2G operation mode can also be used to avoid the circuit breaker trip, i.e., when the $\mathrm{EV}$ is plugged but not in charging and the home loads exceed the nominal power contracted with the service provider, the EV can deliver part of the energy stored in the batteries back to the power grid to avoid the circuit breaker trip. In this operation mode the RF communication also represents an asset to the future smart grids, in order to receive control commands defining its operation. Due to the absence of smart grid to control this operation, the values used in the experimental tests are predefined in the digital controller.

The flowchart in Fig. 3 illustrates the control algorithm behind the V2G operation mode. Despite the benefits of this operation mode, a special care must be taken due to a few restrictions. The main restrictions are associated both with the battery SoC and the compromise assumed between the EV

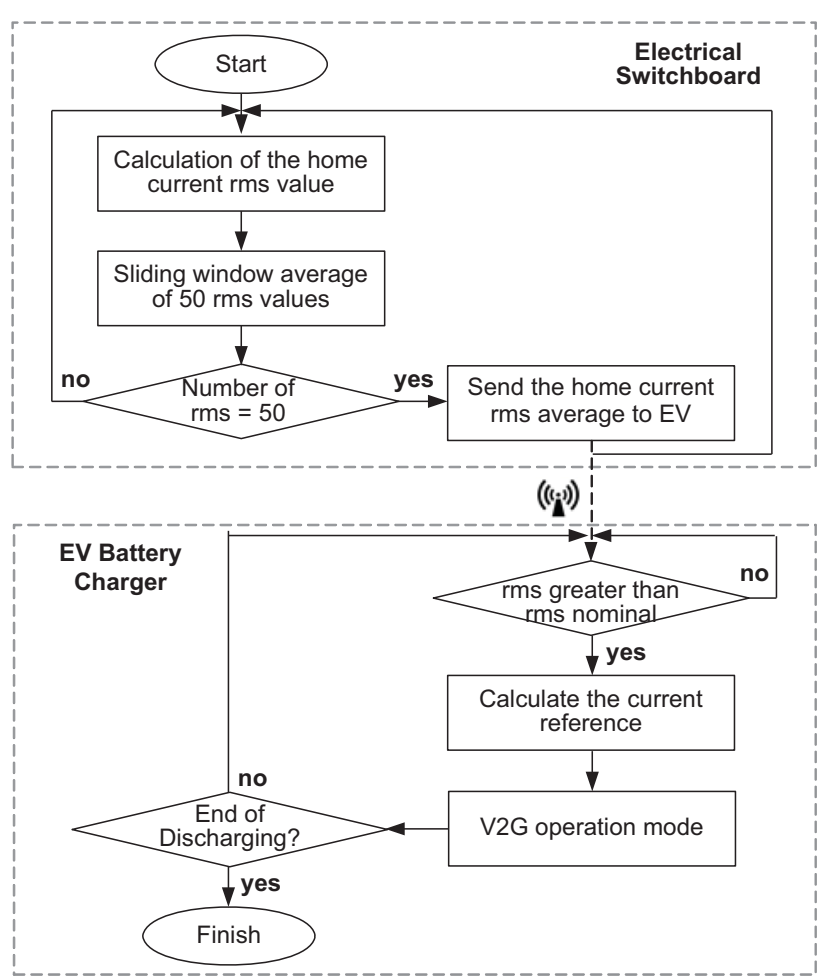

Fig. 3. Control algorithm of the proposed FIDPC architecture during the V2G operation mode.

owner and the power grid service provider. It is interesting to note that this operation mode finds additional advantages in smart grids scenarios, either in reactive power compensation [26], or through an aggregator to regulate the power grid frequency [27], or both.

\section{CASE Study And Simulation Analysis}

In order to illustrate the benefits of the proposed FIDPC it was monitored the battery charging of the EV Renault Fluence [28]. This process was monitored several times in different conditions (e.g., performing the battery charging process after a full discharge and with different ambient temperatures), using a Yokogawa DL708E digital oscilloscope and a FLUKE 435 Power Quality Analyzer. Fig. 4 shows the circuit breaker trip that occurred during the EV Renault Fluence battery charging process due to an overcurrent caused by the home loads current variation. In this figure, it is shown the grid current $\left(i_{G}\right)$, the home loads current $\left(i_{L D}\right)$, and the EV battery charger current $\left(i_{E V}\right)$. As shown, before the circuit breaker trip, occurred two periods of overcurrent. In the first period of 36 seconds the maximum current was $18 \mathrm{~A}$, and in the second period of 95 seconds the maximum current was $19 \mathrm{~A}$.

Based on this situation and considering the charging profile of the EV Renault Fluence, it was performed a computer simulation (Fig. 5) to illustrate the benefits of the FIDPC strategy. In this simulation it was considered that the EV Renault Fluence battery charging process starts at $8 \mathrm{PM}$. Fig. 5(a) shows the rms values of the mains current of the EV Renault Fluence during a typical charging with the batteries initially full discharged. These values were registered with the FLUKE 435 and used in the computer simulation. It is 


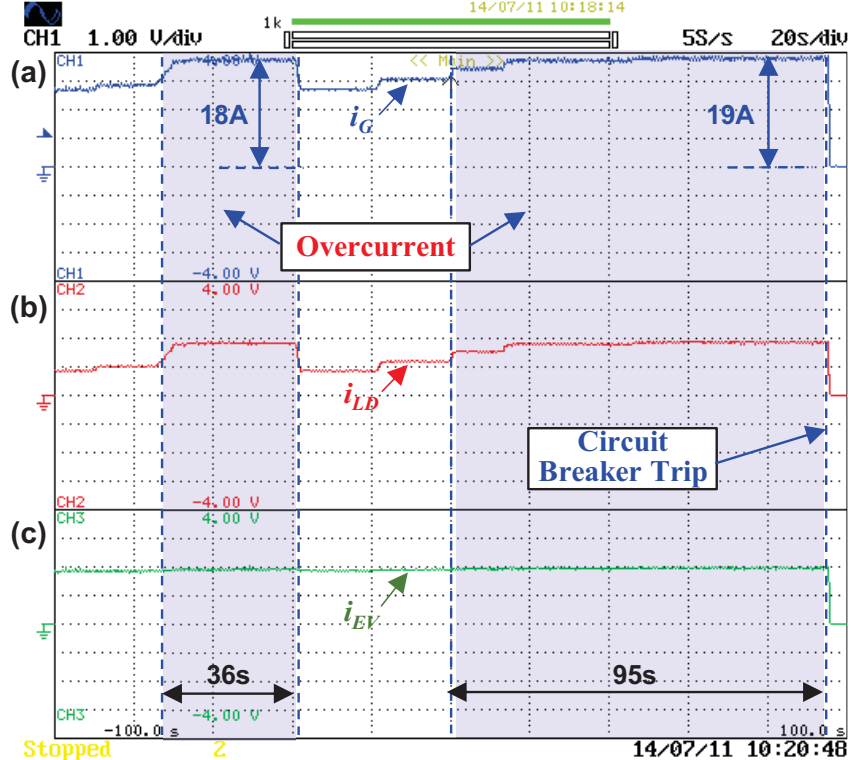

Fig. 4. Example of circuit breaker trip caused by overcurrent during the charge of the EV Renault Fluence: (a) Grid current ( $\left.i_{G}-5 \mathrm{~A} / \mathrm{div}\right)$; (b) Home loads current $\left(i_{L D}-5 \mathrm{~A} / \mathrm{div}\right)$; (c) EV battery charger current $\left(i_{E V}-5 \mathrm{~A} / \mathrm{div}\right)$.

important to note that for obtaining these values it was necessary to disconnect some home loads. In this case, the EV battery charging process started at $8 \mathrm{PM}$ and finished at $4 \mathrm{AM}$, in a total time of 8 hours. As it can be seen, the current was maintained constant and equal to $10 \mathrm{~A}$ almost all the time. The exception to this was observed only in the last 10 minutes, when the current was not constant. It is also important to refer that the Total Power Factor (TPF) was maintained almost unitary $(\mathrm{TPF}=0.99)$ during all the EV battery charging process, and the current was kept almost sinusoidal, with a percentage of Total Harmonic Distortion $\left(\mathrm{THD}_{\mathrm{i}} \%\right)$ of about $5 \%$.

Based on the EV Renault Fluence battery charging profile and considering the typical home load profile represented in Fig. 5(b) (that was also monitored using the FLUKE 435) two distinct situations were simulated. As represented in Fig. 5(b)-(d), it was assumed that the maximum accepted rms value of current is $16 \mathrm{~A}$, which corresponds to the rated current of the main circuit breaker of the home electrical installation. Fig. 5(c) shows the first simulation, without the FIDPC strategy and without disconnect any home loads. As it can be observed in this hypothetical situation, the maximum current of the main circuit breaker is exceeded during 4 hours and the battery charging process cannot be performed in practice. Fig. 5(d) shows the second simulation, with the FIDPC strategy and without disconnect any home loads. As it can be observed, with the FIDPC working, the EV battery charging current was controlled and the charging time is extended until 6:00 AM. In this case, due to the action of the FIDPC, the home current was maintained below the circuit breaker rate, and therefore trips were avoided. Although these results portrayed a specific case, they are quite representative of the EV battery charging process at homes.

Additionally, the proposed FIDPC makes possible to deliver, in controlled way, part of the stored energy in the
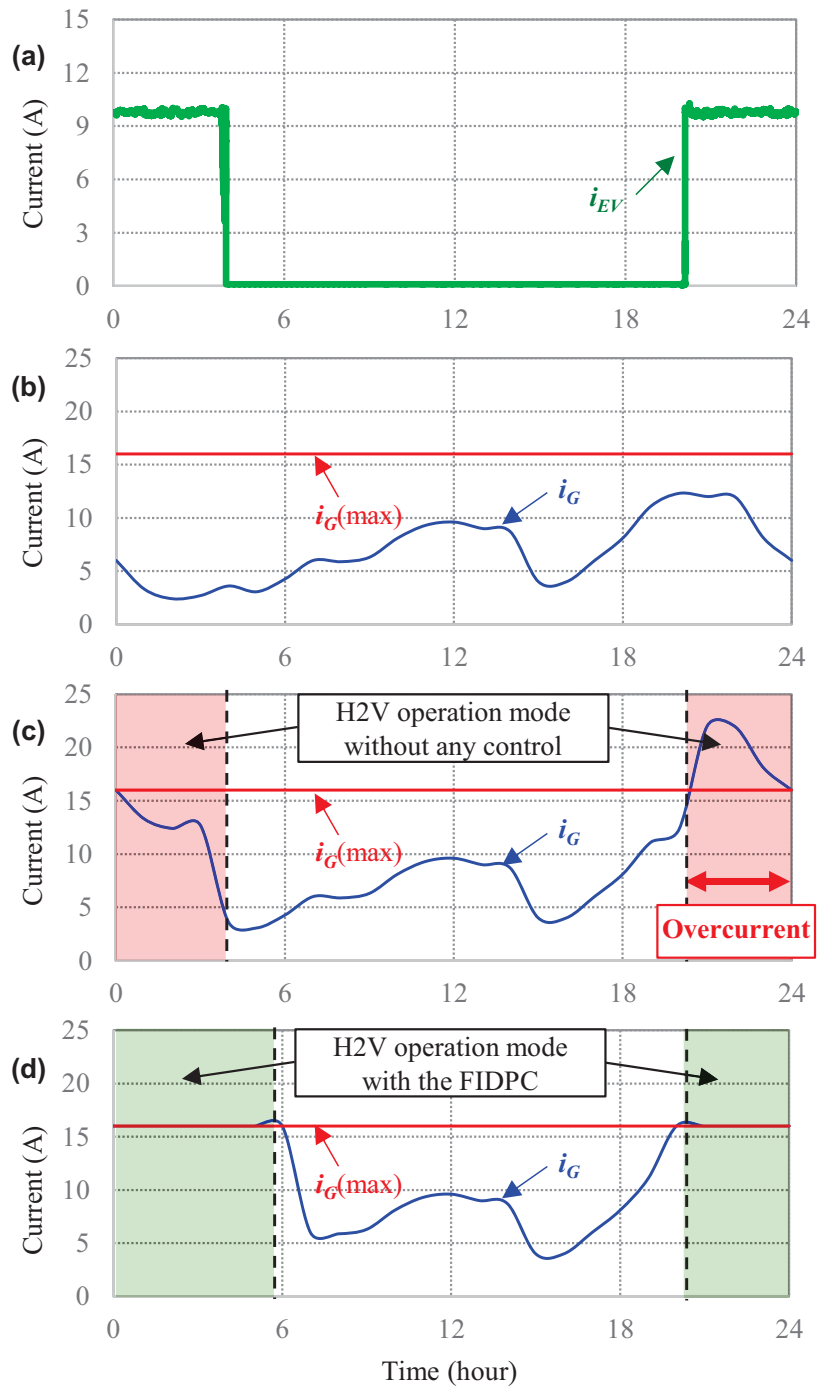

Fig. 5. Comparison results of an EV Renault Fluence charging scenario with and without the proposed FIDPC: (a) EV Renault Fluence charging current profile; (b) Typical daily home load current; (c) H2V operation mode without control; (d) H2V operation mode with the proposed FIDPC.

batteries into the power grid (e.g., working in the V2G operation mode). In a smart grid scenario this operation mode will be controlled by a Collaborative Broker [29]. The H2V and V2G operation modes are carefully described further to complement this analysis.

The charging process of lithium batteries are usually performed in two stages to accomplish with the most of manufacturers recommendations: constant current followed by constant voltage [30][31]. In the first stage, the batteries are charged with constant dc current until the dc voltage reaches the maximum value recommended by the manufacturer. At the end of this stage the batteries are charged to about $80 \%$ of their capacity. After that, during the second stage, the battery charger output voltage is maintained constant until the current approaches zero. This point represents the end of the charging process. The EV battery charger used in this work was designed to follow this strategy and to comply with the recommendations of the manufacturers by controlling the charging current during the first stage and the charging voltage 


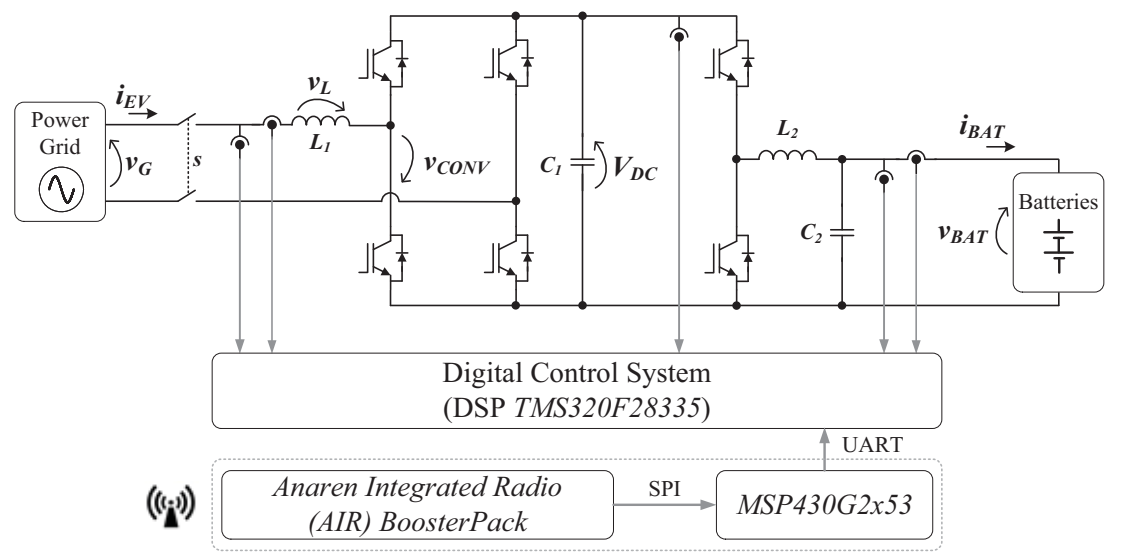

Fig. 6. Electric diagram of the EV battery charger and respective RF link.

during the second stage. As aforementioned, it is mandatory to respect the maximum allowable current of the main circuit breaker in order to avoid trips. This can be done by adjusting the charging current $\left(i_{B A T}\right)$ and voltage $\left(v_{B A T}\right)$ in the batteries (in the dc side of the EV battery charger) towards to control the ac current $\left(i_{E V}\right)$ of the EV battery charger (in the power grid side). This strategy influences the time required to complete a full charge. This influence in the charging time is the price to pay for ensuring that the home electrical energy is never interrupted. Moreover, the EV battery charger predicts an additional safety mechanism to the batteries, by keeping these variables (dc charging current and voltage) within the battery manufacturer recommendations.

\section{SySTEM IMPLEMENTATION}

Fig. 6 shows the electric diagram of the EV battery charger equipped with an RF communication system. In the system implementation are used two RF modules. The first is integrated with the home electrical switchboard to serve as transmitter, and therefore, to send wirelessly the information of the current into the EV battery charger. The second is a piece of hardware, which is an integral part of the EV battery charger, in order to operate as receiver. This hardware is specifically dedicated to meet the approaches aforementioned. The switch $s$ is used to connect/disconnect the EV battery charger to/from the power grid. The EV battery charger auto-disconnects from the power grid in case of voltage sags or swells.

A compromise between cost, size and efficiency was taken into account during the design of the EV battery charger, in order to define the specifications and requirements of the electronic components. This compromise aims the design of a reliable EV battery charger prototype that will be tested in an EV prototype designed by a national company. Table I lists the design specifications of the EV battery charger.

\section{A. Control Algorithms}

Using the proposed strategy to adjust the current of the EV battery charger can result in the occurrence of oscillations in the home current. In this context, two strategies are possible to overcome this problem, and thus, for avoiding the oscillations. In the first strategy, the rms values of the home current are transmitted at a $20 \mathrm{~ms}$ fixed rate (time necessary to calculate the one-cycle rms value). Therefore, this allows modify the reference current of the EV battery charger when sudden variations in the rms value of the home current are present. The digital implementation that allows the calculation of the rms value is given by:

$$
I_{G}[k]=\sqrt{\frac{1}{N} \sum_{k=1}^{k=N} i_{g}{ }^{2}[k],}
$$

where, $N$ is the number of samples in each cycle of the power grid voltage and $k$ denotes the actual sample.

In the second strategy, an alternative methodology to the transmission of the one-cycle rms value is followed by considering an average of $M \mathrm{rms}$ values. These $M \mathrm{rms}$ values are obtained by a sliding window average across the one-cycle rms values. The digital implementation of the sliding sum used in the sliding window is calculated as follows:

$$
\operatorname{sum}[k]=\operatorname{sum}[k-1]-I_{g}{ }^{2}[k-M]+I_{g}{ }^{2}[k] .
$$

Additionally, the average of the rms values $\left(I_{G_{-} A V G}[k]\right)$ of the grid current is calculated using:

$$
I_{G_{-} A V G}[k]=\sqrt{\frac{\operatorname{sum}[k]}{M}} .
$$

The FIDPC proposed in this paper uses the second strategy to adjust the reference current to the EV battery charger. The sliding window uses $M=50$ one-cycle rms values. After the calculation, the average of rms values is transmitted. Each transmitted average value is coded with 8 bits, resulting in a quantization error of $0.125 \mathrm{~A}$ for a maximum of $16 \mathrm{~A}$ power grid current. Additionally, the EV battery charger applies a margin of slack to compensate these rounding and small load variances inside the home. The FIDPC uses an RF link at $868 \mathrm{MHz}$ to transmit the average of rms values from the electrical switchboard towards the EV battery charger. This carrier frequency belongs to the ISM (Industrial, Scientific and Medical) band was selected due to these issues: the commercial availability at large scale of RF modules and its freedom of usage without the need of a specific license of operation. 
TABLE I

EV BATTERY CHARGER SPECIFICATIONS

\begin{tabular}{lll}
\hline \hline Parameters & Value & Unit \\
\hline Input ac Voltage & $230 \pm 10 \%$ & $\mathrm{~V}$ \\
ac Frequency & $50 \pm 1 \%$ & $\mathrm{~Hz}$ \\
Maximum Input ac Current & 16 & $\mathrm{~A}$ \\
Input ac Current Ripple & 0.5 & $\mathrm{~A}$ \\
Maximum Input Power & 3.6 & $\mathrm{kVA}$ \\
Total Power Factor @ Full Load & 0.99 & \\
THDi @ Full Load & $<3 \%$ & $\mathrm{~V}$ \\
Battery Voltage Range & $270-360$ & $\mathrm{~A}$ \\
Maximum Battery Charging Current & 10 & $\mathrm{~mm}$ \\
Efficiency & $>90 \%$ & \\
Dimensions & $250 \times 290 \times 95$ & \\
\hline \hline
\end{tabular}

Fig. 7 presents the control block diagram of the EV battery charger. Fig. 7(a) shows the control diagram that allows the adjustment of the reference current for performing the EV battery charging process as function of the rms current required by the loads at home. The dc-link voltage $\left(v_{D C}\right)$ is adjusted to their voltage reference $\left(v_{D C}{ }^{*}\right)$ through a controller programmed for a PI (Proportional and Integral) action. The power reference $\left(P_{D C}{ }^{*}\right)$ is then obtained from:

$$
P_{D C}^{*}=k_{p}\left(v_{D C}{ }^{*}-v_{D C}\right)+k_{i} \int\left(v_{D C}{ }^{*}-v_{D C}\right) d t .
$$

The power in the dc side to charge the batteries is expressed by:

$$
P_{B A T}{ }^{*}=i_{B A T} v_{B A T},
$$

and the active power reference for the ac side is expressed by:

$$
P^{*}=P_{B A T}{ }^{*}+P_{D C}{ }^{*} \text {. }
$$

The rms value of the reference current $\left(I_{E V}{ }^{*}\right)$ of the EV battery charger is calculated as:

$$
I_{E V}^{*}=\frac{P^{*}}{V_{G}},
$$

where, $V_{G}$ is the rms value of the power grid voltage. The rms value of the reference current $\left(I_{E V}{ }^{*}\right)$ is function of the instantaneous reference current $\left(i_{B A T}{ }^{*}\right)$ and voltage $\left(v_{B A T}{ }^{*}\right)$ to charge the batteries. The instantaneous reference current $\left(i_{E V}{ }^{*}\right)$ must be in phase with the fundamental component of the power grid voltage $\left(v_{G}\right)$. This is achieved multiplying that quantity by a reference signal $\mathrm{pll}$, whose amplitude is unitary. This reference signal $(p l l)$ is obtained from a Phase-Locked Loop [32]. Then, the reference current is affected by the gain of $\sqrt{2}$ as follows:

$$
i_{E V}{ }^{*}=\sqrt{2} I_{E V}{ }^{*} p l l .
$$

As shown in Fig. 7(b), the synthesizing of the instantaneous reference current $\left(i_{E V}{ }^{*}\right)$ is done with the help of a current control strategy, as described in [33]. Fig. 6 allows to establish the following equation: (a)

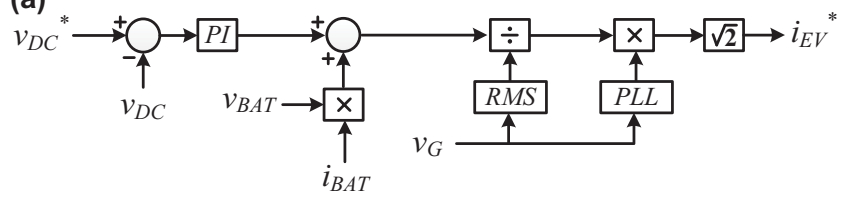

(b)

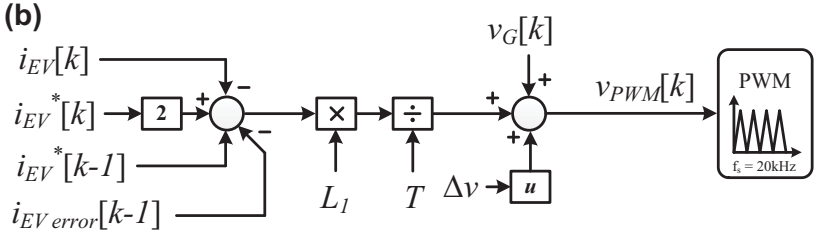

(c)

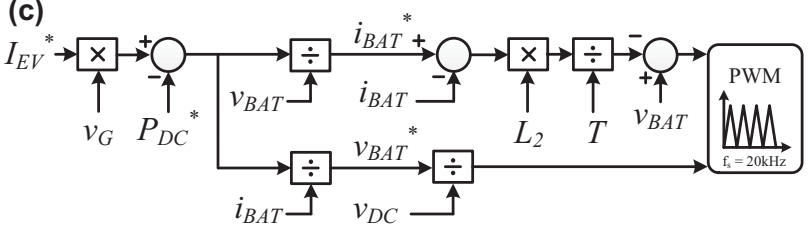

Fig. 7. Control block diagram of the EV battery charger: (a) Dc-link voltage control and EV battery charger current reference; (b) Current control technique and unipolar PWM modulator; (c) Battery current or voltage control.

$$
v_{G}=v_{L}+v_{C O N V}
$$

where, $v_{L}$ is the inductance voltage and $v_{C O N V}$ the voltage produced by the bidirectional converter. The instantaneous current error $\left(i_{\text {EVerror }}\right)$ is function of the instantaneous current reference $\left(i_{E V}{ }^{*}\right)$ and the instantaneous current measured $\left(i_{E V}\right)$. The expression of $i_{\text {EVerror }}$ is given by:

$$
i_{E V \text { error }}=i_{E V}{ }^{*}-i_{E V} \text {. }
$$

Equation (9) can be rewritten in terms of (10), resulting on:

$$
v_{C O N V}=-L_{1} \frac{d i_{E V}^{*}}{d t}+L_{1} \frac{d i_{\text {EVerror }}}{d t}+v_{G} .
$$

The high sampling frequency $(40 \mathrm{kHz})$ that is used allows the approximation of the two derivatives in the equation (11) by functions with linear variation. Thus, the voltage $\left(v_{C O N V}\right)$ produced by the converter can be expressed in terms of the discrete samples as:

$$
\begin{aligned}
v_{C O N V}[k]= & v_{G}[k]-\frac{L_{1}}{T}\left(2 i_{E V}{ }^{*}[k]-i_{E V}{ }^{*}[k-1]\right. \\
& \left.-i_{E V}[k]-i_{\text {EVerror }}[k-1]\right),
\end{aligned}
$$

where, $T$ is the sampling period. Then, the gate pulse patterns are obtained through a unipolar sinusoidal Pulse Width Modulation (PWM) strategy with a $20 \mathrm{kHz}$ center aligned triangular carrier. To mitigate the dead-time effect was used a strategy that consists in adding a constant value $(\Delta v)$ to the voltage reference $\left(v_{\mathrm{CONV}}\right)$ during the positive semi-cycle, and subtracting the same value during the negative semi-cycle:

$$
v_{P W M}{ }^{*}[k]=v_{\text {CONV }}[k]+u \Delta v,
$$

where, $\Delta v$ is the voltage to compensate the dead-time effect, and $u$ assumes one of these following values: 
TABLE II

MAIN COMPONENTS SELECTED TO THE BATTERY CHARGER

\begin{tabular}{lll}
\hline \hline Component & Model / Value & Quantity \\
\hline DSP & $T M S 320 F 28335$ & 1 \\
IGBT & $F G A 25 N 120 A N T D$ & 6 \\
IGBT Drivers & $H C P L 3120$ & 6 \\
Snubber Capacitor & $1 \mu \mathrm{F} / 1000 \mathrm{~V}$ & 3 \\
Inductor $L_{1}$ & $5 \mathrm{mH} / 16 \mathrm{~A}$ & 1 \\
Capacitor $C_{1}$ & $680 \mu \mathrm{F} / 450 \mathrm{~V}$ & 4 \\
Inductor $L_{2}$ & $300 \mu \mathrm{H} / 15 \mathrm{~A}$ & 1 \\
Capacitor $C_{2}$ & $680 \mu \mathrm{F} / 450 \mathrm{~V}$ & 1 \\
Current Sensor & $\mathrm{LA} 55-\mathrm{P}$ & 2 \\
Voltage Sensor & $\mathrm{LV} 25-\mathrm{P}$ & 3 \\
\hline \hline
\end{tabular}

$$
u=\left\{\begin{array}{ll}
1 & , i_{E V}{ }^{*}>0 \\
-1 & , i_{E V}{ }^{*}<0
\end{array} .\right.
$$

Fig. 7(c) shows the block diagram of the battery current and voltage control. In order to control the charging current, the dc-dc converter must produce the voltage $\left(v_{P W M} D C^{*}\right)$, according to:

$$
v_{P W M_{-} D C}{ }^{*}[k]=v_{B A T}[k]+\frac{L_{2}}{T}\left(i_{B A T}{ }^{*}[k]-i_{B A T}[k]\right) .
$$

On the other hand, the process to control the charging voltage directly affects the duty cycle $(\delta)$ in the dc-dc converter as follows:

$$
\delta[k]=\frac{v_{B A T}{ }^{*}[k]}{v_{D C}[k]} .
$$

Additionally, it must be referred that is selected the frequency of $20 \mathrm{kHz}$ for the triangular carrier in the PWM of the dc-dc converter.

\section{B. EV Battery Charger Hardware}

The implemented $3.6 \mathrm{kVA}$ EV battery charger is composed by two bidirectional power converters: an ac-dc converter and a dc-dc converter. In both converters are used IGBTs (model FGA25N120ANTD), i.e., four in the bidirectional ac-dc converter and two in the reversible dc-dc converter. A snubber capacitor (with $0.1 \mu \mathrm{F} / 1000 \mathrm{~V}$ ) is placed in parallel to each leg to minimize the voltage stress across the semiconductors. Each leg of the ac-dc converter operates with a $20 \mathrm{kHz}$ switching frequency (unipolar PWM), resulting on a frequency $\left(f_{s}\right)$ in the coupling inductance of $40 \mathrm{kHz}$. It is used an inductor of $5 \mathrm{mH}$ for obtaining a maximum ac current ripple $\left(\Delta i_{E V}\right)$ of $0.5 \mathrm{~A}$. This value is obtained according:

$$
\Delta i_{E V}=\frac{v_{D C}}{8 L_{1} f_{s}} .
$$

A capacitor of $2.7 \mathrm{mF}$ is used to maintain the oscillation in the dc-link voltage below $10 \mathrm{~V}$. This value is obtained according to:

$$
\Delta v_{D C}=\frac{2 V_{G} I_{E V}}{\omega C_{1} V_{D C}}
$$

The $\mathrm{L}_{2} \mathrm{C}_{2}$ filter is connected to the output of the dc-dc converter for keeping the maximum output voltage ripple below to $0.1 \mathrm{~V}$. The selected elements for this filter are an inductor of $300 \mu \mathrm{H}$ and a capacitor of $680 \mu \mathrm{F}$. The calculation of these elements obeyed to the following equation:

$$
L_{2} C_{2}=\frac{\left(v_{D C}-v_{B A T}\right) v_{B A T}}{8 f_{S}{ }^{2} v_{D C} \Delta v_{B A T}} .
$$

Table II lists the main components that are used in the EV battery charger prototype. The topology that is used in the EV battery charger design imposes sinusoidal current in the ac side during both $\mathrm{H} 2 \mathrm{~V}$ and $\mathrm{V} 2 \mathrm{G}$ modes. The control system for implementing the $\mathrm{H} 2 \mathrm{~V} / \mathrm{V} 2 \mathrm{G}$ algorithms is composed by several electronic circuits with analogue and digital signals. The algorithms in the digital control system are implemented in a Digital Signal Processor (DSP) TMS320F28335 (from Texas Instruments). This DSP contains two internal Analog-to-Digital Converters (ADC) with eight channels each. These ADCs receive both voltages and currents signals that are provided by the signal conditioning circuit. The voltage and current signals of the bidirectional power converter are obtained through hall-effect sensors (from the LEM manufacturer) in the signal conditioning circuit. An offset must be added to all the bipolar signals (including the current $i_{B A T}$ ) because the ADCs are unipolar. It is also used a circuit to provide protection against overvoltages and overcurrents on both sides of the power converters. It must be noted that are also used Transient Voltage Surge Suppressors (TVSS) to protect the EV battery charger against lightning. The control signals to the IGBT drivers are provided by the command circuit, which receives the control signals from the DSP. Currently, the operation of the EV battery charger occurs in accordance with the orders given by the user through the external interface. Additionally, the EV battery charger is prepared for future functionalities. One of these added functionalities is for example the possibility to be controlled by a Collaborative Broker in smart grids, which will define when the EV battery charger works either as H2V or as V2G. Fig. 8 shows the setup used to obtain the experimental results. More specifically, the photography in Fig. 8(a) shows the final aspect of the developed EV battery charger, whereas the photography in Fig. 8(b) shows the RF communication system that is implemented in the home electrical switchboard. Fig. 8(c) shows the whole tested system.

\section{Communication System}

An Anaren Integrated Radio (AIR) BoosterPack module is used to integrate the core-elements that compose the FIDPC. More specifically, the AIR module is used to establish the RF connectivity between the home electrical switchboard and the EV battery charger. Such communication module is composed by the on-board $A 110 L R 09 A$ radio module that integrates an antenna to operate in the European $868 \mathrm{MHz}$ ISM band, and by the Texas Instruments CC110L transceiver. The AIR BoosterPack is a low power wireless transceiver extension module. 

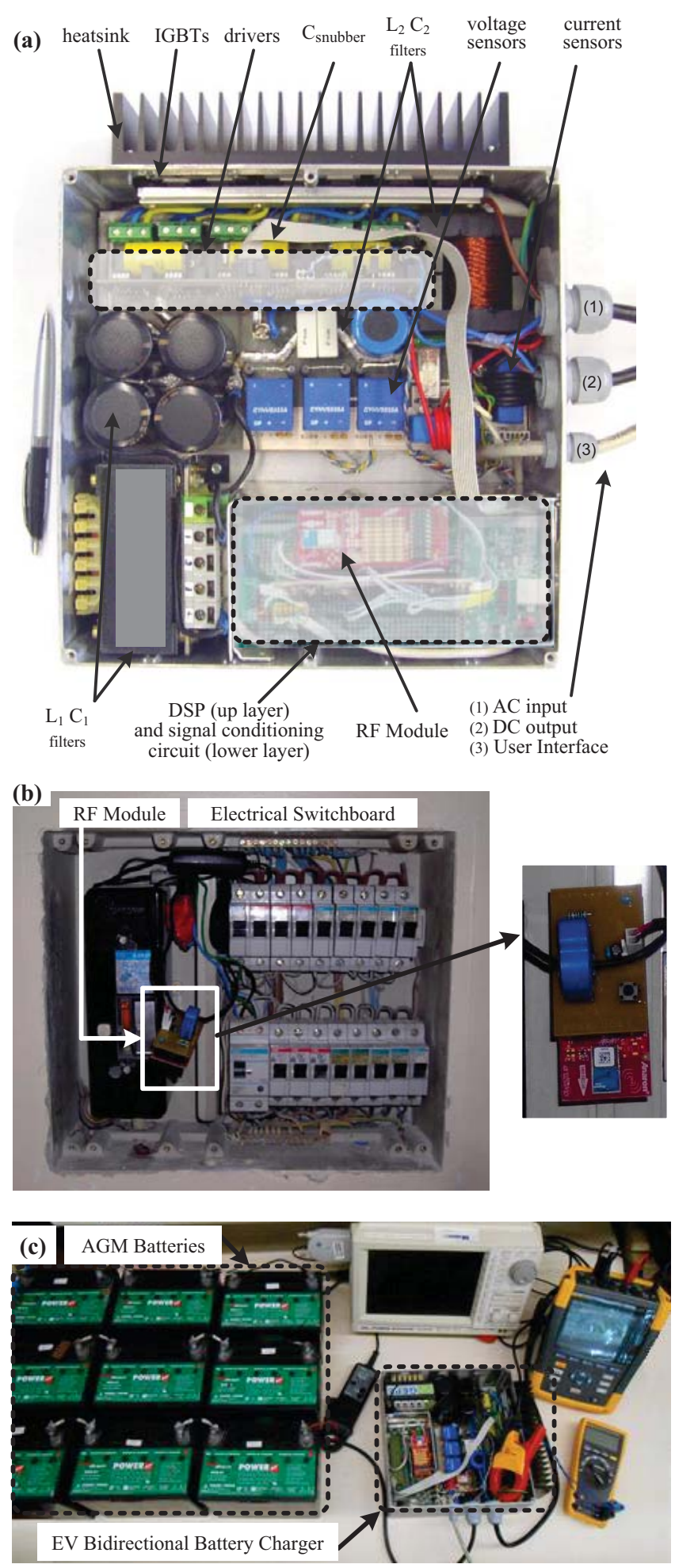

Fig. 8. Setup used to obtain the experimental results: (a) Developed EV battery charger; (b) RF communication system implemented in the home electrical switchboard; (c) Workbench of the tested system.

In the EV battery charger, the AIR BoosterPack exchange data with a microcontroller model MSP430G2x53 through a Serial Peripheral Interface (SPI). This microcontroller exchange data with the DSP through a Universal Asynchronous Receiver Transmitter (UART) interface. In the

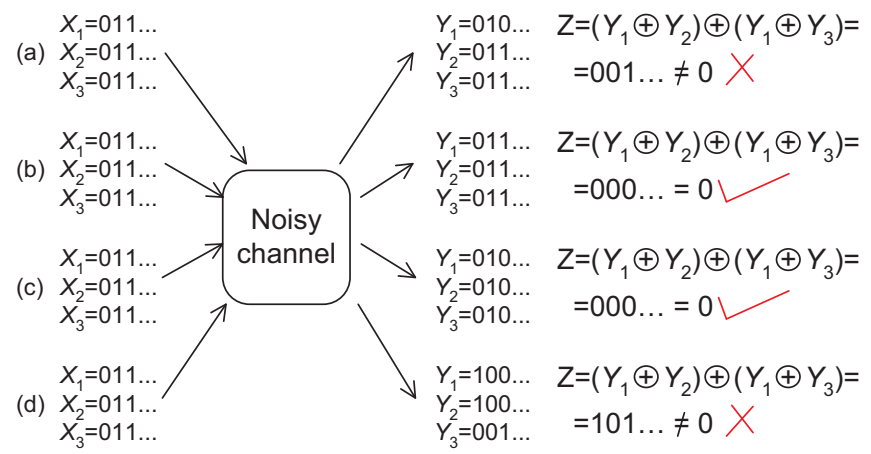

Fig. 9. Representation of four examples of the transmission and reception of four rms values.

home's electrical switchboard, the AIR BoosterPack establishes communication with the MSP430G2x53 (microcontroller from Texas Instruments) through a SPI interface.

The home loads current is measured through a current sensor model LTSR 15 NP from the LEM manufacturer. This current is then adjusted through a signal conditioning circuit, and its value is further acquired by the MSP430G2x53 microcontroller through an ADC channel at fixed sampling rate. Finally, the sliding average of $50 \mathrm{rms}$ values is calculated and sent towards the EV battery charger in order to adjust the setpoints of the EV battery charging process.

The AIR BoosterPack module is used to transmit the rms value of the home loads current to the EV battery charger. The digital data acquired with the ADC $(10$ bits $)$ of the MSP430G2x53 is converted to an rms value (as explained before) and further coded and transmitted in a single character of 8 bits. Each data character is transmitted three times to allow the receiver to detect errors and to take preventive actions with its relation. This means that effectively to transmit a single rms value, a transmission of three characters is required. The data characters are received, analyzed and obtained by the EV battery charger and then, the corresponding rms value for the ac side of EV battery charger $\left(i_{E V}{ }^{*}\right)$ is determined and used in the $\mathrm{H} 2 \mathrm{~V}$ (or V2G) algorithms. Fig. 9 illustrates four examples of the transmission and reception of few rms values. The label $X 1$ corresponds to the binary representation of the main character, whereas the labels $X 2$ and $X 3$ correspond to the binary representation of the two characters that will allow the possible error detection. In normal operation the errors are not present, therefore, in the receiver's side $Y 1=Y 2=Y 3$ (as it happens in the transmitter's side with $X 1=X 2=X 3$ ). The effect of errors can be modeled generically as $Y=X \oplus E$, where $E$ is the error pattern [34]. In a situation without errors, $Y=X \oplus E=X$ and thus, $E=0$. The presence of errors is analyzed in the receiver through XOR operations on the received characters $X 1, X 2$ and $X 3$. These operations are performed by the hardware on $\{Y 1, Y 2, Y 3\}$ as follows: $Z=(Y 1 \oplus Y 2) \oplus(Y 1 \oplus Y 3)$. If $Z=0$, then the transmission errors are not present, or as will be analyzed further, there is a presence of a false error-free situation. Nonetheless, the EV battery charger must be ready to deal with this situation.

In the first case (a), the third bit of $X 1$ is corrupted by an 
error, but because $Y 2=Y 3$ then $Z=0$, meaning that $Y=X=011 \ldots$ In this case, if the received rms value is smaller than the previous, the EV battery charger maintains the last value until receive a new value. As seen further in the third example, this take of action from the EV battery charger is important to prevent overcurrent due to a false error-free. In the second case (b), all the characters are received without errors. The take of actions from the EV battery charger remains for an rms value smaller than the previously received. In the third case (c), all the characters are transmitted with the same error, and consequently it is verified that the received characters are without errors. This is a case of a false error-free. In this case, if the rms value is higher than the previously received, the EV battery charger automatically decreases the current needed for charging the batteries. Otherwise, the EV battery charger must wait the receiving of a new rms value to confirm the absence of overcharge before raising the current need for charging the batteries. Without this "intelligent" action, the power grid current could exceed the maximum value contracted. It must be noted that fortunately, this kind of errors are extremely rare [34]. In the last case (d) none of the characters are received correctly and therefore, the error is easily detected and the EV battery charger maintains the previous current reference.

\section{EXPERIMENTAL RESUltS}

Several field tests were performed under realistic conditions to analyze the performance of the FIDPC in general and of the EV battery charger in particular. The EV battery charger is dedicated to charge lithium batteries, however, it can be used to charge any type of batteries. The experimental results presented in this paper were obtained with a set of 24 sealed 12 V 33 Ah Absorbed Glass Mat (AGM) batteries, connected in series in order to obtain a nominal voltage of $288 \mathrm{~V}$ and a capacity of $9.5 \mathrm{kWh}$. The results were registered with a Yokogawa DL708E digital oscilloscope, acquiring the signal at a sampling frequency of $1 \mathrm{ksps}$. The voltage from the power grid was acquired and visualized before making the tests with the FIDPC. The voltage presents distortion in its waveform (in the maximum and minimum amplitudes), due to the great amount of nonlinear loads connected upstream of the home electrical switchboard under test. Additionally, the nonlinear loads inside the home also contribute to this voltage distortion. Nevertheless, in both operation modes $(\mathrm{H} 2 \mathrm{~V}$ and $\mathrm{V} 2 \mathrm{G})$ the current at the bidirectional EV battery charger is kept as a sinusoidal waveform, avoiding any contribution to the voltage distortion.

\section{A. Steady State Operation}

The experimental results obtained with the developed prototype in steady state operation are shown in Fig. 10, Fig. 11, Fig. 12, and Fig. 13. Fig. 10(a) shows the power grid voltage $\left(v_{G}\right)$ and the EV battery charger current $\left(i_{E V}\right)$ during the battery charging process (i.e., with the EV battery charger working in the $\mathrm{H} 2 \mathrm{~V}$ mode). Fig. 10(b) presents the same voltage and current $\left(v_{G}\right.$ and $\left.i_{E V}\right)$, when part of the energy previously stored in the batteries of the EV is delivered back to the power grid ( $\mathrm{EV}$ battery charger in the V2G mode).

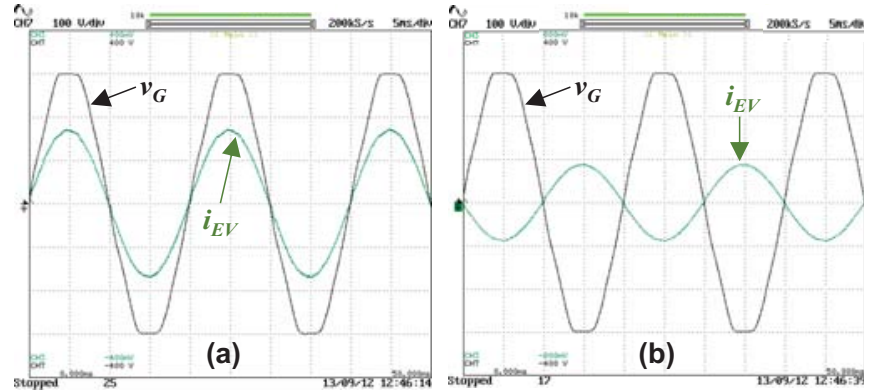

Fig. 10. Experimental results in steady state of the power grid voltage $\left(v_{G}-100 \mathrm{~V} /\right.$ div $)$ and the EV battery charger current $\left(i_{E V}-10 \mathrm{~A} /\right.$ div $)$ in: (a) $\mathrm{H} 2 \mathrm{~V}$ operation mode; (b) V2G operation mode.

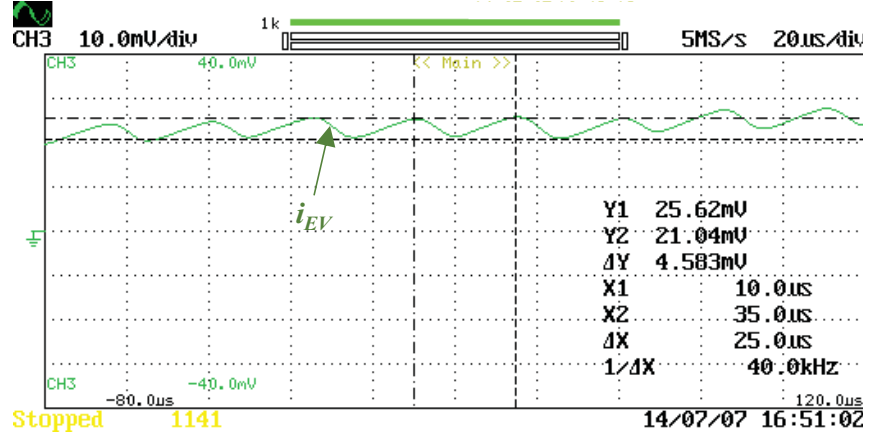

Fig. 11. Detail of the EV battery charger current ripple (1 A/div, $20 \mathrm{~ms} /$ div $)$ (for a switching frequency of $40 \mathrm{kHz}$ ).

Fig. 11 shows in detail the ac current ripple $(0.5 \mathrm{~A})$ and the switching frequency $(40 \mathrm{kHz})$. It can be observed a current with sinusoidal shape in the ac side of EV battery charger, when working on both modes. This is an important contribution towards the preservation of the power quality. In the $\mathrm{H} 2 \mathrm{~V}$ mode, the current is in phase with the voltage, whereas in the $\mathrm{V} 2 \mathrm{G}$ mode, the phase turns by an angle of $180^{\circ}$, becoming in phase opposition with relation to the voltage.

Fig. 12 shows the power grid voltage $\left(v_{G}\right)$, the grid current $\left(i_{G}\right)$, the home loads current $\left(i_{L D}\right)$, and the EV battery charger current $\left(i_{E V}\right)$. It is possible to observe in this last figure that the voltage is slightly distorted, while the current in the loads is highly distorted, and the EV battery charger current is sinusoidal.

Fig. 13 shows the spectral analysis and the $\mathrm{THD}_{\mathrm{i}} \%$ of the grid current $\left(i_{G}\right)$ for two cases: (a) with the EV battery charger working in $\mathrm{H} 2 \mathrm{~V}$ mode (i.e., with the $\mathrm{EV}$ batteries being charged), and (b) without the EV battery charger in operation. It was observed a reduction of $6 \%$ (from $31.9 \%$ to $25.9 \%$ ) in the $\mathrm{THD}_{\mathrm{i}} \%$ of the grid current, when the EV battery charger was working and operating with sinusoidal current. These values were specific of the operating conditions, namely the type of loads that were used, and at the same time of the sinusoidal charging current waveform at the EV battery charger. Undoubtedly, it was observed and validated the fact that the EV battery charger contributes to preserve the power quality.

\section{B. Transient Response}

Fig. 14 shows the transient response of the EV battery charger in function of a decrement in the home loads current. In this situation, the EV battery charger increases the charging 


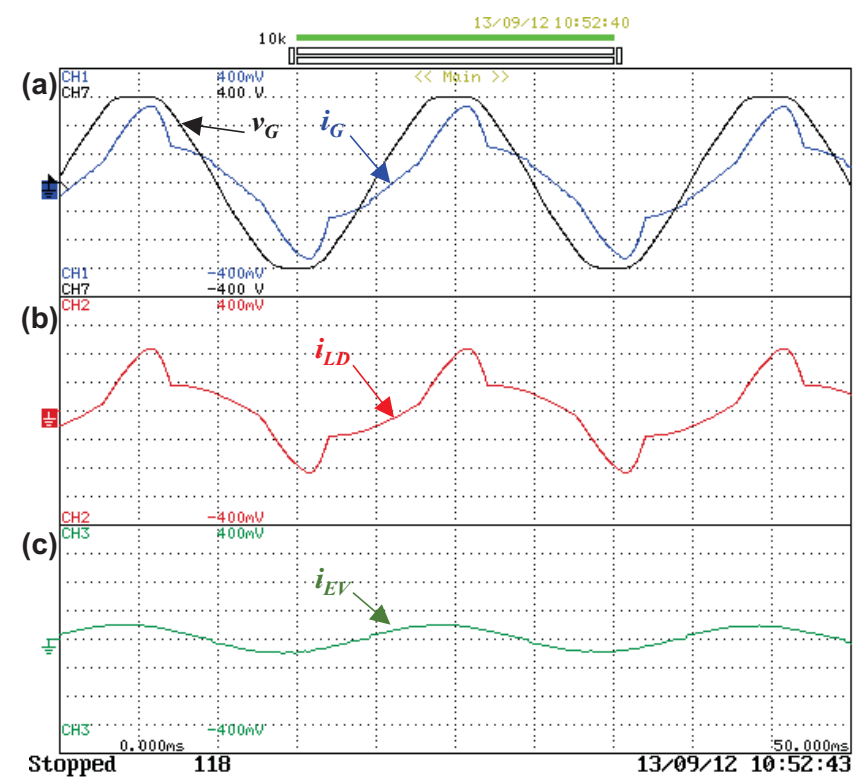

Fig. 12. Experimental results showing the EV battery charger in steady state operation: (a) Power grid voltage $\left(v_{G}-100 \mathrm{~V} /\right.$ div $)$ and grid current $\left(i_{G}-10 \mathrm{~A} / \mathrm{div}\right)$; (b) Home loads current $\left(i_{L D}-10 \mathrm{~A} / \mathrm{div}\right)$; (c) EV battery charger current $\left(i_{E V}-10 \mathrm{~A} /\right.$ div $)$.

(a)

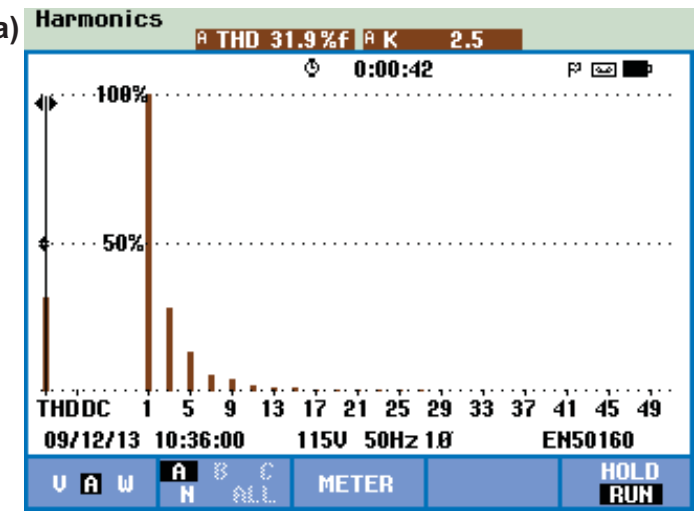

(b)

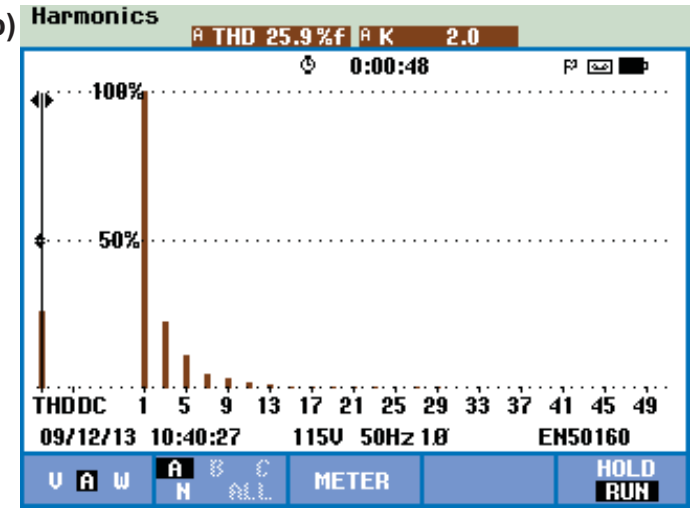

Fig. 13. Spectral analysis and THD\% of the power grid current $\left(i_{G}\right)$ in steady state: (a) Without the EV battery charger $(\mathrm{THD} \%=31.9 \%$ ); (b) With the EV battery charger working in $\mathrm{H} 2 \mathrm{~V}$ mode $(\mathrm{THD} \%=25.9 \%)$.

current $\left(i_{E V}\right)$. However, it can also be observed the absence of sudden variations in the current, which is favorable for the power quality maintenance.

Fig. 15 shows the instantaneous values of the grid current $\left(i_{G}\right)$, the home loads currents $\left(i_{L D}\right)$, and the EV battery charger current $\left(i_{E V}\right)$. This figure shows the transient response (during

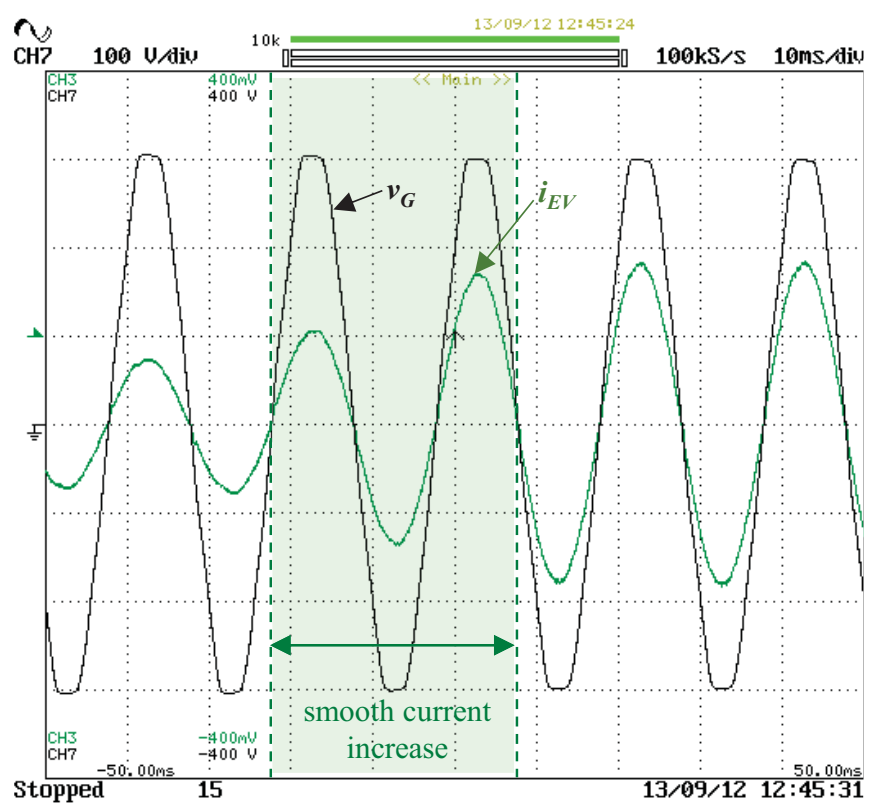

Fig. 14. Experimental results showing the power grid voltage $\left(v_{G}-100 \mathrm{~V} / \mathrm{div}\right)$ and the transient response of the EV battery charger current $\left(i_{E V}-10 \mathrm{~A} / \mathrm{div}\right)$ in function of a decrement in the home loads current.

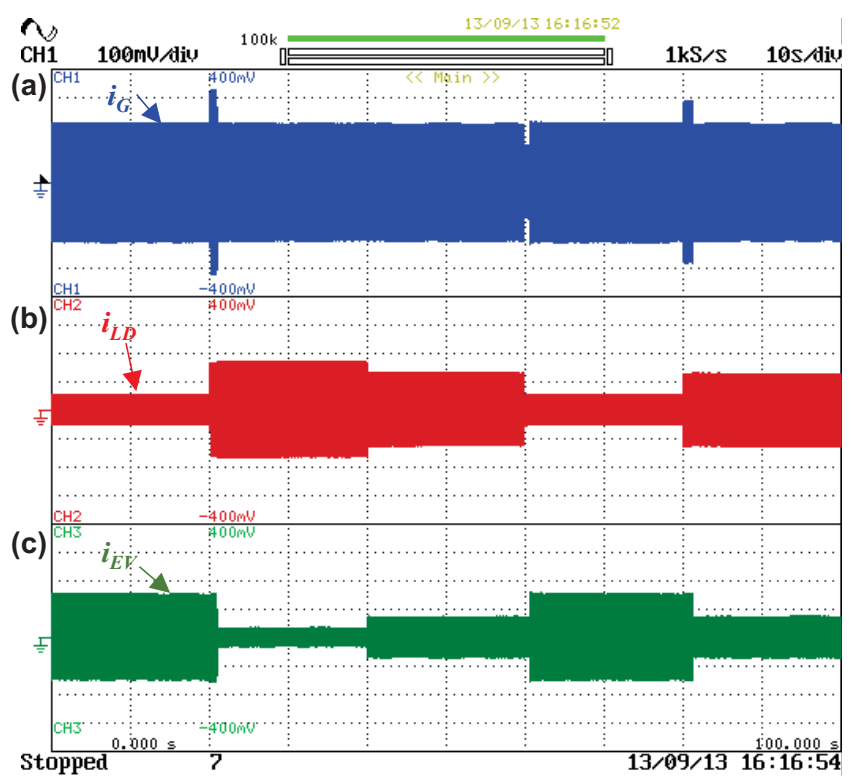

Fig. 15. Experimental results showing the transient response of the instantaneous values during several load variations in a short time interval of $100 \mathrm{~s}$ during the operation in H2V: (a) Grid current $\left(i_{G}-10 \mathrm{~A} /\right.$ div); (b) Home loads current $\left(i_{L D}-10 \mathrm{~A} / \mathrm{div}\right)$; (c) EV battery charger current $\left(i_{E V}-10 \mathrm{~A} / \mathrm{div}\right)$.

$100 \mathrm{~s}$ ) of the EV battery charger in function of several changes in the home loads current. In this case, the EV battery charger current $\left(i_{E V}\right)$ is adjusted to a new value with a smooth response, after elapsing the delay needed to calculate the rms value of the home loads current $\left(i_{L D}\right)$. As shown, the grid current $\left(i_{G}\right)$ is kept almost constant and equal to $16 \mathrm{~A}$. As shown in Fig. 15(b), the maximum current variation in the loads is $10 \mathrm{~A}$. It is important to refer that the grid current $\left(i_{G}\right)$ reached $23 \mathrm{~A}$ for a very short period, which occurred during the delay to calculate the rms value and its further transmitted towards the EV battery charger. As usually circuit breakers 


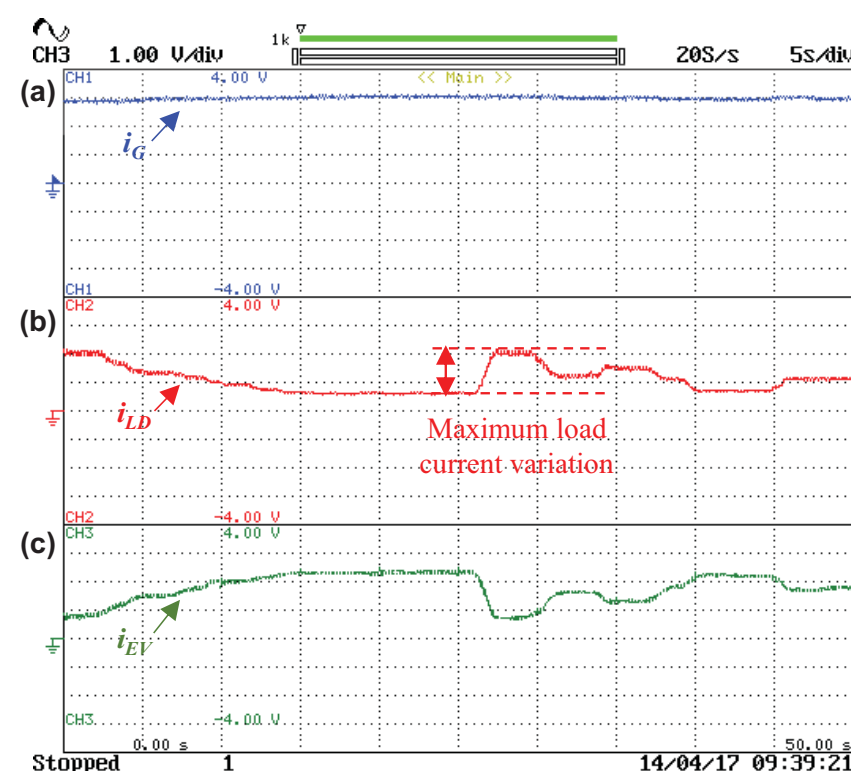

Fig. 16. Experimental results showing the transient response of the one cycle rms values of current during several load variations in a short time interval of $50 \mathrm{~s}$ during the operation in $\mathrm{H} 2 \mathrm{~V}$ mode: (a) Grid current $\left(i_{G}-5 \mathrm{~A} / \mathrm{div}\right)$; (b) Home loads current $\left(i_{L D}-5 \mathrm{~A} / \mathrm{div}\right) ;$ (c) EV battery charger current $\left(i_{E V}-5 \mathrm{~A} / \mathrm{div}\right)$.

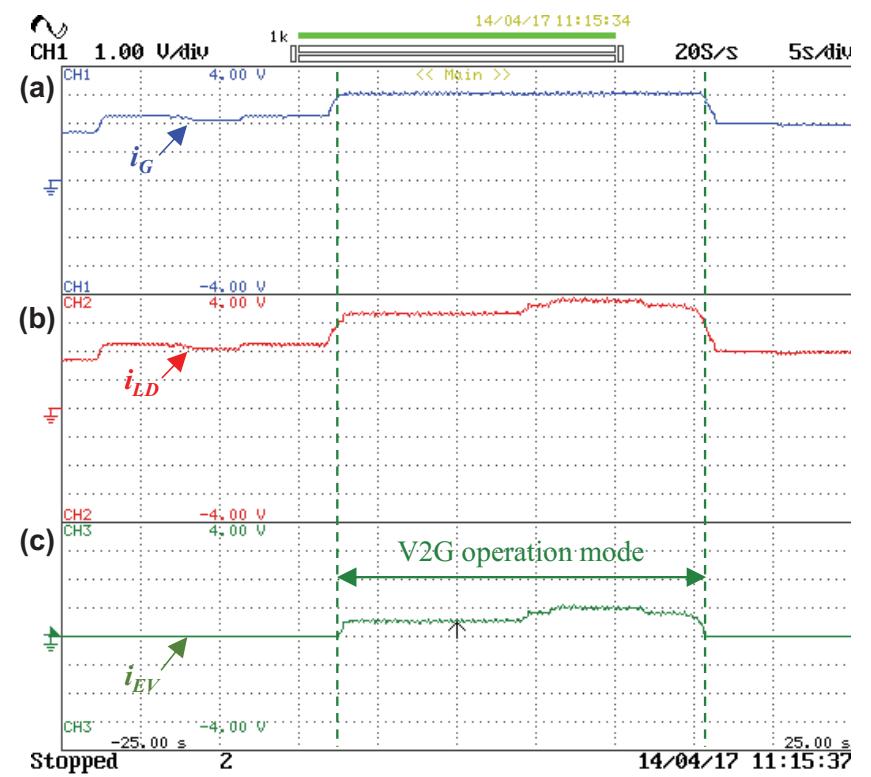

Fig. 17. Experimental results showing the transient response of the one cycle $\mathrm{rms}$ values during several load variations in a short time interval of $50 \mathrm{~s}$ and during the operation in V2G: (a) Grid current $\left(i_{G}-5 \mathrm{~A} / \mathrm{div}\right)$; (b) Home loads current $\left(i_{L D}-5 \mathrm{~A} /\right.$ div); (c) EV battery charger current $\left(i_{E V}-5 \mathrm{~A} /\right.$ div $)$.

operate by thermal losses, the rms values of current above the nominal value (16 $\mathrm{A}$ in the presented case) are allowed during short periods of time without tripping. Fortunately, this means that higher values of currents during the rms calculation delay can be easily accommodated by the circuit breaker of the home. Fig. 16 shows the one cycle rms values of the grid current $\left(i_{G}\right)$, of the home loads current $\left(i_{L D}\right)$, and of the EV battery charger current $\left(i_{E V}\right)$. It can be observed in this figure that the controller of the EV battery charger adjusts the current with a smooth response, avoiding fast current variations that can be problematic to the electric installation. In this situation,

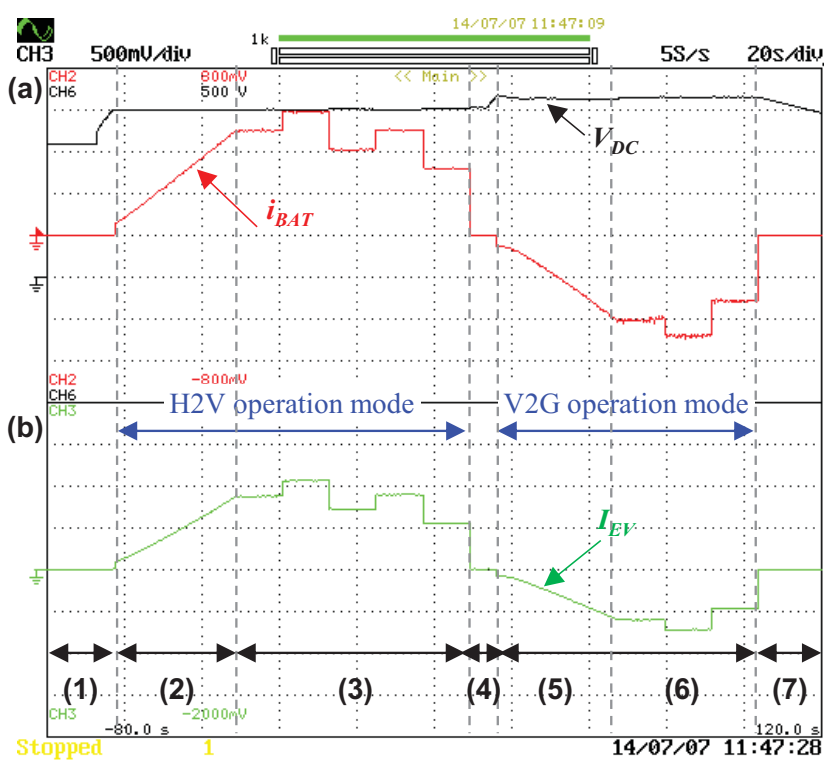

Fig. 18. Experimental results showing a transient response in a time interval of $200 \mathrm{~s}$ during $\mathrm{H} 2 \mathrm{~V}$ and V2G operation modes: (a) Dc-link voltage $\left(v_{D C}-100 \mathrm{~V} /\right.$ div $)$ and battery charging current $\left(i_{B A T}-2 \mathrm{~A} /\right.$ div $)$; (b) Rms value of the EV battery charger current $\left(i_{E V}-2 \mathrm{~A} /\right.$ div $)$.

the grid current was maintained almost constant and equal to $16 \mathrm{~A}$, while the loads current experienced a variation of $7 \mathrm{~A}$.

As aforementioned, the EV can be used to provide energy to the power grid (V2G operation mode) due to its possibility to operate in bidirectional mode. Therefore, this operation mode can also be used to avoid trips in the circuit breaker when the home current exceeds the maximum allowed value that was specified. It is possible to confirm this situation in Fig. 17. In this case the EV is plugged and not in charge. The EV starts the operation as V2G, when the rms value of the home loads current $\left(i_{L D}\right)$ exceeds the maximum allowed. Consequently, it is also possible to confirm in Fig. 17(a) that the rms value of the grid current $\left(i_{G}\right)$ does not exceed the maximum current of the circuit breaker (16 A).

Fig. 18 shows the experimental results of the FIDPC transient response $(200 \mathrm{~s}$ ) during the $\mathrm{H} 2 \mathrm{~V}$ and $\mathrm{V} 2 \mathrm{G}$ operation modes. Fig. 18(a) shows the dc-link voltage $\left(v_{D C}\right)$ and the current to charge the batteries $\left(i_{B A T}\right)$. Fig. 18(b) shows the rms value of the EV battery charger current. This result was registered to illustrate the beginning of the battery charging process, the adjusting of the charging current according to the aforementioned algorithms, and the beginning of the battery discharging process. According to this figure, in stage (1), the dc-link voltage $\left(v_{D C}\right)$ was controlled to its voltage reference $(360 \mathrm{~V})$ with energy provided by the EV batteries. After this stage, the EV battery charger was connected to the power grid and the dc-link voltage $\left(v_{D C}\right)$ was controlled to a new reference value $(400 \mathrm{~V})$. The stage (2) starts when the dc-link voltage $\left(v_{D C}\right)$ reaches the new reference voltage. Then, the battery charging current $\left(i_{B A T}\right)$ increases slowly. During the stage (3), the battery charging current $\left(i_{B A T}\right)$ was adjusted according to the FIDPC control algorithm. This last statement was the reason for the current vary during this stage. During the stage (4) the battery charging process was interrupted and the dc-link voltage was controlled to a new voltage reference 
$(430 \mathrm{~V})$. This higher voltage value in the dc-link was necessary to achieve a sine wave current in the ac side, when delivering energy back to the power grid. The stage (5) have initiated after the dc-link voltage $\left(v_{D C}\right)$ reached the new voltage reference $(430 \mathrm{~V})$. In this fifth stage, the battery discharging current increased slowly. During the stage (6), the battery discharge current was adjusted according to the FIDPC control algorithm. This explains why the battery discharge current was always changing along this entire stage. Finally, the V2G operation mode was stopped in the stage (7).

\section{Discussion}

As expected, it is possible to confirm that the ac current in the EV battery charger is sinusoidal, when the experimental results were taken in steady state during the $\mathrm{H} 2 \mathrm{~V}$ and $\mathrm{V} 2 \mathrm{G}$ operation modes. Additionally and considering the $\mathrm{H} 2 \mathrm{~V}$ operation mode, it is possible to confirm that the EV battery charger is clearly able to adjust the current in function of the rms values received from the electrical switchboard through the RF communication. It is also important to note that the current waveform is not affected during the transient response, i.e., this current remains sinusoidal and at the same time, the total power factor is kept unitary. The proposed FIDPC was validated in a particular case, but it can be generalized to address this solution to a set of cases. For such purpose, it is enough to install an RF transmitter in the electrical switchboard where the EV is plugged. Therefore, the battery charging process of an EV can be controlled according to the power limits of the installation where it is plugged.

\section{CONCLUSIONS}

This paper presents a Flexible Infrastructure for Dynamic Power Control (FIDPC) of Battery Chargers for Electric Vehicles (EVs), which is designed taking into account the context of the smart grids. An innovative strategy for dynamic power control of an EV battery charger is presented and associated to the proposed FIDPC. The developed prototype allows the dynamic adjustment of the rms value of the EV battery charger current in response to changes in the current required by the other loads of the home. The communication between the home electrical switchboard and the EV is supported by RF communication, which simplifies the installation process. The behavior of the EV battery charger prototype was evaluated through realistic conditions. At last, but not least, it can be concluded that this FIDPC supported on RF communication is an interesting solution to apply in smart homes, contributing to the reliability and expansion of smart grids.

\section{REFERENCES}

[1] Farzad Rajaei Salmasi, "Control Strategies for Hybrid Electric Vehicles: Evolution, Classification, Comparison, and Future Trends," IEEE Trans. Veh. Technol., vol.56, no.5, pp.2393-2404, Sept. 2007.

[2] Seshadri Srinivasa Raghavan, Alireza Khaligh, "Electrification Potential Factor: Energy-Based Value Proposition Analysis of Plug-In Hybrid Electric Vehicles," IEEE Trans. Veh. Technol., vol.61, no.3, pp.10521059, Mar. 2012.
[3] Ahmed Yousuf Saber, Ganesh Kumar Venayagamoorthy, "Plug-in Vehicles and Renewable Energy Sources for Cost and Emission Reductions," IEEE Trans. Ind. Electron., vol.58, no.4, pp.1229-1238, Apr. 2011.

[4] Shuang Gao, K.T.Chau, Chunhua Liu, Diyun Wu, C. C. Chan, "Integrated Energy Management of Plug-in Electric Vehicles in Power GridWith Renewables," IEEE Trans. Veh. Technol., vol.63, no.7, pp.3019-3027, Sept. 2014.

[5] Fabian Kennel, Daniel Görges, Steven Liu, "Energy Management for Smart Grids With Electric Vehicles Based on Hierarchical MPC," IEEE Trans. Ind. Informat., vol.9, no.3, pp.1528-1537, Aug. 2013.

[6] Alireza Khaligh, Zhihao Li, "Battery, Ultracapacitor, Fuel Cell, and Hybrid Energy Storage Systems for Electric, Hybrid Electric, Fuel Cell, and Plug-In Hybrid Electric Vehicles: State of the Art," IEEE Trans. Veh. Technol., vol.59, no.6, pp.2806-2814, July 2010.

[7] Ernesto Inoa, Jin Wang, "PHEV Charging Strategies for Maximized Energy Saving," IEEE Trans. Veh. Technol., vol.60, no.7, pp.29782986, Sept. 2011.

[8] Nian Liu, Jinshan Chen, Lin Zhu, Jianhua Zhang, Yanling He, “A Key Management Scheme for Secure Communications of Advanced Metering Infrastructure in Smart Grid," IEEE Trans. Ind. Electron., vol.60, no.10, pp.4746-4756, Oct. 2013.

[9] Malabika Basu, Kevin Gaughan, Eugene Coyle, "Harmonic distortion caused by EV battery chargers in the distribution systems network and its remedy," International Conference UPEC - Universities Power Engineering Conference, pp.869-873, Jan. 2004.

[10] Sanjaka G.Wirasingha, Ali Emdai, "Classification and Review of Control Strategies for Plug-In Hybrid Electric Vehicles," IEEE Trans. Veh. Technol., vol.60, no.1, pp.111-122, Jan. 2011.

[11] João A. Peças Lopes, Filipe Soares, Pedro M. Rocha Almeida, "Integration of Electric Vehicles in the Electric Power Systems," Proc. IEEE, vol.99, no.1, pp.168-183, Jan. 2011.

[12] Tian Zhang, Wei Chen, Zhu Han, Zhigang Cao, "Charging Scheduling of Electric VehiclesWith Local Renewable Energy Under Uncertain Electric Vehicle Arrival and Grid Power Price,” IEEE Trans. Veh. Technol., vol.63., no.6, pp.2600-2612, July 2014.

[13] Kevin J. Dyke, Nigel Schofield, Mike Barnes, "The Impact of Transport Electrification on Electrical Networks," IEEE Trans. Ind. Electron., vol.57, no.12, pp.3917-3926, Dec. 2010.

[14] José Joaquín Escudero-Garzás, Ana García-Armada, Gonzalo SecoGranados, "Fair Design of Plug-in Electric Vehicles Aggregator for V2G Regulation," IEEE Trans. Veh. Technol., vol.61, no.8, pp.34063419, Oct 2012.

[15] Robert Smolenski, Marcin Jarnut, Grzegorz Benysek, Adam Kempski, "AC/DC/DC Interfaces for V2G Applications-EMC Issues," IEEE Trans. Ind. Electron., vol.60, no.3, pp.930-935, Mar. 2013.

[16] Matthias D. Galus, Stephan Koch, Göran Andersson, "Provision of Load Frequency Control by PHEVs, Controllable Loads, and a Cogeneration Unit," IEEE Trans. Ind. Electron., vol.58, no.10, pp.4568-4582, Oct. 2011.

[17] M. El Chehaly, Omar Saadeh, C. Martinez, G. Joos, "Advantages and Applications of Vehicle to Grid Mode of Operation in Plug-In Hybrid Electric Vehicles," IEEE EPEC Power and Energy Conference, pp.1-6, Oct. 2009.

[18] Vehbi C. Gungor, Dilan Sahin, Taskin Kocak, Salih Ergut, Concettina Buccella, Carlo Cecati, Gerhard P. Hancke, "Smart Grid and Smart Homes - Key Players and Pilot Projects," IEEE Ind. Electron. Mag., vol.6, pp.18-34, Dec. 2012

[19] Chunhua Liu, K. T. Chau, Diyun Wu, Shuang Gao, "Opportunities and Challenges of Vehicle-to-Home, Vehicle-to-Vehicle, and Vehicle-toGrid Technologies," Proc. IEEE, vol.101, no.11, pp.2409-2427, Nov. 2013.

[20] Chenrui Jin, Jian Tang, Prasanta Ghosh, "Optimizing Electric Vehicle Charging: A Customer's Perspective,” IEEE Trans. Veh. Technol., vol.62, no.7, pp.2919-2927, Sept. 2013.

[21] Ding Li, Sudharman K. Jayaweera, "Distributed Smart-Home DecisionMaking in a Hierarchical Interactive Smart Grid Architecture," IEEE Trans. Parallel Distrib. Syst., vol.26, no.1, pp.75-84, Jan. 2015. 
[22] Ding Li, Sudharman K. Jayaweera, "Machine-Learning Aided Optimal Customer Decisions for an Interactive Smart Grid," IEEE Syst. J., vol.PP, no.99, pp.1-12, 2014

[23] Hal Turton, Filipe Moura, "Vehicle-to-grid systems for sustainable development: An integrated energy analysis," ELSEVIER Technological Forecasting and Social Change, vol.75, no.8, pp.1091-1108, Oct. 2008.

[24] Kristien Clement-Nyns, Edwin Haesen, Johan Driesen, "The Impact of Charging Plug-In Hybrid Electric Vehicles on a Residential Distribution Grid,” IEEE Trans. Power Syst., vol.25. no.1, pp.371-380, Feb. 2010.

[25] Zhijun Shang, Shijie Cui Quishi Wang, Hongyu Zhang, Weichun Ge, "On Applications of Short Distance RF for Smart Grid at Distribution Level," IEEE International Symposium on Instrumentation and Measurement, Sensor Network and Automation, pp.584-587, Dec. 2013.

[26] Mithat C. Kisacikoglu, Burak Ozpineci, Leon M. Tolbert, "Examination of a PHEV Bidirectional Charger System for V2G Reactive Power Compensation," IEEE APEC Applied Power Electronics Conference and Exposition, pp.458-465, Feb. 2010.

[27] Sekyung Han, Soohee Han, Kaoru Sezaki, "Development of an Optimal Vehicle-to-Grid Aggregator for Frequency Regulation,” IEEE Trans. Smart Grid, vol.1, no.1, pp.65-72, June 2010.

[28] J. Martins, F. P. Brito, D. Pedrosa, Vítor Monteiro, João L. Afonso, "Real-Life Comparison between Diesel and Electric Car Energy Consumption," in Grid Electrified Vehicles: Performance, Design and Environmental Impacts, 1st ed., Carla Alexandra Monteiro da Silva, Ed. Nova Science Publishers, 2013, Chapter 10, pp.209-232. .

[29] João C. Ferreira, A. Silva, Vítor Monteiro, João L. Afonso. "Collaborative Broker for Distributed Energy Resources," in Computational Intelligence and Decision Making, 1st ed., A.Madureira, C.Reis, V.Marques, Ed. Springer, 2013, pp.367-378.

[30] Ala Al-Haj Hussein, Issa Batarseh, "A Review of Charging Algorithms for Nickel and Lithium Battery Chargers,” IEEE Trans. Veh. Technol., vol.60, no.3, pp.830-838, Mar. 2011.

[31] Winston Battery, "Lithium Battery datasheet WB-LYP90AHA," Charge and Discharge Chart, Jan. 2007.

[32] Masoud Karimi-Ghartemani, "Linear and Pseudolinear Enhanced Phased-Locked Loop (EPLL) Structures," IEEE Trans. Ind. Electron. vol.61, no.3, pp.1464-1474, Mar. 2014.

[33] S. Orts-Grau, F. J. Gimeno-Sales, A. Abellan-Garcia, S. Segui-Chilet, J. C. Alfonso-Gil, "Improved Shunt Active Power Compensator for IEEE Standard 1459 Compliance," IEEE Trans. Power Del., vol.25, no.4, pp.2692-2701, Oct. 2010.

[34] A. Bruce Carlson, "Communication Systems: An Introduction to Signals and Noise in Electrical Communication," 4th ed. McGraw-Hill, New York, 2002

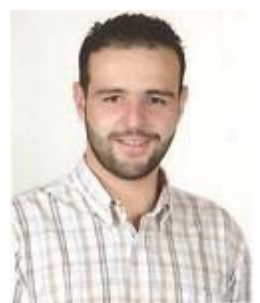

Vítor Monteiro (S'10) was born in Guimarães, Portugal, in May of 1984. He received the M.Sc. degree in industrial electronics and computer engineering from the University of Minho, Guimarães, in 2012 . He is currently working toward the Ph.D. degree with the University of Minho. Since 2008, he has been a member of the Group of Energy and Power Electronics (GEPE) and a collaborator with Centro Algoritmi, University of Minho. His research interests include power electronic converters, digital control techniques, smart grids, and electric vehicles. Mr. Monteiro received a Doctoral Scholarship from the Foundation for Science and Technology of Portugal.

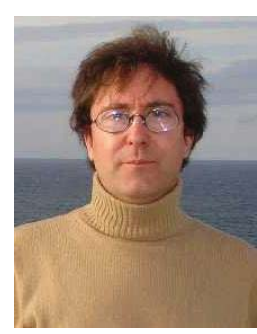

João Paulo Carmo was born in 1970 at Maia, Portugal. He graduated in 1993 and received his MSc degree in 2002, both in Electrical Engineering from the University of Porto, Portugal. In 2007, he obtained the $\mathrm{PhD}$ degree in Industrial Electronics from the University of Minho, Portugal. Nowadays since 2014, he is Professor in the University of São Paulo (USP), Brazil. He is involved in the research on micro/nanofabrication technologies for mixed-mode/RF and optic systems, solid state integrated sensors, microactuators, micro/nanodevices for use in biomedical and industrial applications. Professor Carmo is also the vice-director of the Metamaterials-Microwaves and Optics Group, University of São Paulo (USP), Brazil, was well as collaborator in the MEMS-UMinho (MicroElectroMechanical Systems) R\&D Centre, University of Minho, Portugal.

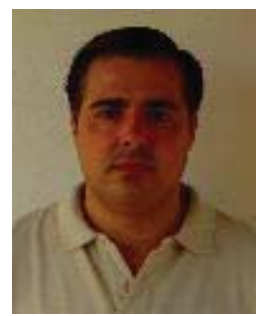

J. G. Pinto (S'06) was born in Guimarães, Portugal, in 1977. He received the B.Sc. degree in Electronics Engineering and the M.Sc. degree in Industrial Electronics from the University of Minho, Portugal, in 2001 and 2004, respectively. From 2002 to 2006 worked as invited Assistant Lecturer at the Electrical Department of the Polytechnic Institute of Bragança, Portugal. From 2006 to 2012 he worked as a researcher at the Group of Energy and Power Electronics (GEPE) of the Centro Algoritmi, at the University of Minho. He received the $\mathrm{PhD}$ degree in Electronics and Computer Engineering from the University of Minho, in 2012. Since 2013 he works as invited Assistant Professor at the Industrial Electronics Department of the University of Minho. His research interests are related with Power Electronics, Power Quality and Digital Control of Power Converters.

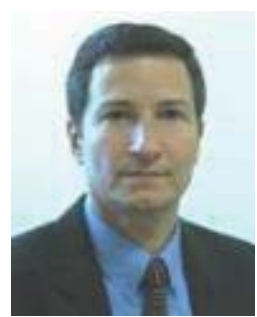

João Luiz Afonso (M'00) was born in Rio de Janeiro, Brazil, in 1963. He received the B.S. and M.Sc. degrees in Electrical Engineering from the Federal University of Rio de Janeiro in 1986 and 1991, respectively, and the Ph.D. degree in Industrial Electronics from the University of Minho, Guimarães, Portugal, in 2000. Since 1993, he has been with the Department of Industrial Electronics, University of Minho, where he is Associate Professor. He teaches Electrical Machines, Electrical Energy Systems, Complements of Power Electronics, Electrical Power Quality, Active Power Filters and Renewable Energy. He is a researcher with the Group of Energy and Power Electronics (GEPE), and he coordinates the thematic strand of Sustainable and Smart Cities of the Centro Algoritmi. His research interests include: Power Quality, Active Power Filters, Renewable Energy, Electric Vehicles, Energy Efficiency, Energy Storage Systems, Smart Grids and Smart Cities. 